\title{
The body is designed to be healthy- a case for eating real food
}

\section{Opinion}

Consider this: it is possible to be both overfed and undernourished. This statement might seem contradictory but unfortunately it is one that describes far too many people. The diseases that plague us today are those of affluence, largely influenced by lifestyle. Heart disease, type 2 diabetes and certain cancers are among the leading causes of mortality in this country. I just watched the documentary Hungry for Change (2012) and immediately felt compelled to share a few of key points. I encourage you to watch it in full.

The documentary unveils practices of the food industry that have led to a food supply we must consider with a critical eye. Just take a walk through the supermarket - no really, open your eyes to the plethora of chips, cereals, sodas, etc. and then try reading the ingredients, all of them because that is what goes inside your body when you consume these highly processed foods. The problem doesn't end with the packaged food section but rather extends into the meat section, dairy, even produce. One has to question the purity of food raisedwith growth hormones, fed unnatural diets, sprayed with pesticides or injected with various genes. The food available has the potential to make us sick and that is a hard pill to swallow. Perhaps we have become all too familiar with swallowing pills, but I like to think not all hope is lost.

The documentary provides straight forward advice: "if it is made in a lab then it takes a lab to digest." The idea is that if we start to add the good stuff into our diet, naturally the bad stuff will be forced out. If we go a step further and hone in on how the food makes us feel then we won't even want to go back to the processed junk food, diet sodas and diet food. The body requires a certain intake of daily vitamins, minerals, nutrients, essential proteins and fats that we must obtain from our diet and when we fail to provide these the body sends signals that it still needs something- it is still hungry. The body can be "starving on a cellular level"as described in the documentary, even with overconsumption of empty calories.

Take fat free Snackwell's cookies for example. The cookies gained popularity during the whole "fat free" food craze but, as with most fat free items, when fat is taken out sugar is added to replace. Read the ingredients and you will find enriched flour, partially hydrogenated oils, emulsifiers, several forms of sugar and several highly processed oils. The issue with enriched flours is the original vitamins, minerals,
Volume 2 Issue 4 - 2015

\author{
Lauren Zimmerman \\ Registered Dietitian, Summerville Medical Center, USA
}

Correspondence: Lauren Zimmerman, Registered Dietitian for cardiac and preventative health, Summerville Medical Center, 295 Midland Pkwy, Summerville, SC 29485, United States, Email laurenannzimmerman@yahoo.com

Received: May II, 2015 | Published: May 27, 2015

bran and germ are stripped during the processing to yield a product with a long shelf-life. But the body needs these nutrients and since grains are a great source, they are added back in in order to prevent deficiencies. We then consume the flour with vitamins and minerals added in by manufacturing companies instead of how nature designed.

Nature provides an abundance of fruit, vegetables, grains, nuts and seeds that offer a balance of nutrients and minerals in addition to antioxidants and phytonutrients. These plant nutrients protect our bodies from free radical damage to cells that can trigger a downward spiral into health problems. We can think of this as nature's gift to us.

The body wants to be healthy; it is designed to be healthy, always detoxing. So in adapting to a whole food based diet, make small changes even one at a time and with time these changes will improve overall health and reduce risk for disease. Drink clean water, breathe clean air, eat an abundance of plant based foods, responsibly raised and grown food, get adequate sleep and maintain an active lifestyle. The skin is a symbol of health because it is the last place to receive nutrients. The health of your skin, nails and hair all looks better when you are eating better. So if we eat for health than our outward appearance will reflect inner health.

\section{Acknowledgements}

None.

\section{Conflict of interest}

The author declares no conflict of interest. 